\section{GRP-065 EVALUATION OF OCCUPATIONAL EXPOSURE TO ANTINEOPLASTIC DRUGS IN PHARMACY AND ONCOLOGY DEPARTMENT}

doi:10.1136/ejhpharm-2013-000276.065

'E Korczowska, 'H Jankowiak-Gracz, ${ }^{2}$ PJM Sessink, ${ }^{3} E$ Grzeskowiak. 'Clinical Hospital of Lord's Transfiguration The University of Medical Sciences, Pharmacy, Poznan, Poland; 2Exposure Control Sweden AB, Bohus-Björkö, Sweden; ${ }^{3}$ Poznan University of Medical Sciences, Department of Clinical Pharmacy and Biopharmacy, Poznan, Poland

Background Several studies have shown evidence of adverse health effects associated with exposure to antineoplastic drugs. Hospital personnel involved in preparation and administration of antineoplastic drugs may be at risk if exposed to these hazardous pharmaceuticals.

Purpose The purpose of the study was to evaluate the potential exposure to antineoplastic drugs in the pharmacy and oncology departments in a Polish hospital under normal working conditions. The exposure was measured by determining cyclophosphamide (CP) in the urine of pharmacists, physicians and nurses.

Materials and Methods Eight hospital workers were included in the study. Urine samples were collected from 2 pharmacists, 2 physicians and 4 nurses. One pharmacist prepared antineoplastic drugs while the other pharmacist assisted. All four nurses in the oncology department were engaged in the administration of the drugs. The two physicians did not handle the drugs but they came in contact with treated patients. Total $24 \mathrm{~h}$ urine was collected in fractions and from each fraction the volume was recorded and used to calculate the total amount of CP excreted over the $24 \mathrm{hr}$ period. Samples were collected with Cyto Urine Kits from Exposure Control Sweden AB. Samples were stored frozen until analysis with GC-MSMS.

Results Over the $24 \mathrm{hr}$ periods, 62 urine samples from 8 hospital workers were collected. CP was detected in 31 urine samples $(50 \%)$ involving all pharmacists, all physicians and 3 nurses. The total amount of CP excreted per worker ranged from 106 to $500 \mathrm{ng} / 24 \mathrm{hr}$. The mean amount of CP excreted per worker on group basis was $234 \mathrm{ng} / 24 \mathrm{hr}$ (physicians: $343 \mathrm{ng} / 24 \mathrm{hr}$, pharmacists: $239 \mathrm{ng} / 24 \mathrm{hr}$, nurses: $177 \mathrm{ng} / 24 \mathrm{hr}$ ). The highest amount of CP excreted was found for one physician (500 $\mathrm{ng} / 24 \mathrm{hr}$ ) and for one nurse (492 ng/24 hr). The amount of CP excreted in urine from the pharmacist who assisted in preparation (358 $\mathrm{ng} / 24 \mathrm{hr}$ ) was higher than from the pharmacist who prepared the chemotherapy infusions $(120 \mathrm{ng} / 24 \mathrm{hr})$. CP was not detected in the urine samples of one nurse indicating no measurable exposure to $\mathrm{CP}$.

Conclusions The results show that almost all hospital workers tested were exposed to CP. In addition, the study demonstrates the highest exposure of personnel not directly involved in the preparation and administration of antineoplastic drugs. Clearly, more research is needed, but this is sufficient evidence that nurses and physicians involved in the area of cytotoxic administration on the ward can also be exposed to these hazardous drugs.

No conflict of interest.

\section{GRP-066 EVALUATION OF PHARMACEUTICAL CARE ISSUES IN THE ASEPTIC PREPARATION UNIT AT A TERTIARY CARE HOSPITAL: A FOCUS ON CHEMOTHERAPY PRESCRIBING AND PREPARATION}

doi:10.1136/ejhpharm-2013-000276.066

S Shafiq, A Taqi. Sultan Oaboos University Hospital, Pharmacy, Muscat, Oman

Background Medicines errors associated with high-risk agents such as chemotherapy drugs may have significant outcomes. At Sultan Qaboos University Hospital (SQUH), the aseptic preparation unit (APU) is responsible for preparing chemotherapy and Total Parenteral Nutrition (TPN) preparations. The number of total chemotherapy orders has doubled over the past two years. Due to increased consumption, cost and complexity of regimes, it is important to for a chemotherapy-verifying pharmacist (CVP) to cheque all chemotherapy prescriptions prior to preparation.

Purpose The aim of the study was to describe and evaluate pharmaceutical care interventions, focusing on chemotherapy prescribing and preparation at SQUH.

Materials and Methods This retrospective descriptive study was based in the APU of SQUH. It covered a total time frame of February 2011 to March 2012, which was divided into two periods of 7 months of pre- and post-CVP involvement. The interventions were evaluated for type and cost.

Results During the study, 159 interventions were documented. Monthly interventions increased from 3 to 16 after the involvement of a CVP. Drug dosing (75\%) was the most frequent intervention in the drug regimen category (59.7\%). Interventions in drug selection $(34.6 \%)$ included addition (25\%) and deletion (27\%) of drugs. Around $50 \%$ of the interventions avoided toxicity and $35 \%$ improved efficacy. The financial impact of CVP interventions was evaluated in 59 interventions (37\%). The total cost saved from the 59 interventions was Omani R.O. 18,114 (€36,478). Methotrexate $(12.5 \%)$ was the drug with most frequent interventions. The expensive drug with most frequent interventions was pegylated asparaginase $(4.5 \%)$

Conclusions Chemotherapy verification prior to preparation has been demonstrated to improve safety and efficacy and decrease health care costs. A clinical pharmacist's participation in chemotherapy preparation and prescribing is essential, in order to provide quality care.

No conflict of interest.

\section{GRP-067 EVALUATION OF PROFESSIONAL PRACTISE ON DRUGS PRESCRIPTIONS IN A GERIATRIC UNIT: HOW TO IMPROVE THEM?}

doi:10.1136/ejhpharm-2013-000276.067

${ }^{1} \mathrm{C}$ Straczek, ${ }^{1} \mathrm{C}$ Cordonnier-Jourdin, 'B Berdougo, ${ }^{2} \mathrm{~S}$ Herbaud, ${ }^{2} \mathrm{E}$ Taillandier, ${ }^{1} \mathrm{M}$ Paul. ${ }^{1} \mathrm{CHU}$ Henri Mondor, pharmacy, Creteil, France, ${ }^{2} \mathrm{CHU}$ Henri Mondor, Unité de medecine gériatrique, Creteil, France

Background Elderly patients suffering from many diseases and disorders are more likely to have multiple prescriptions. These multiple prescriptions could result in drug toxicity, reduce compliance and cost a lot.

Purpose Following the French health agency recommendations, we evaluated professional practise on drug prescriptions for very old inpatients of a university hospital.

Materials and Methods All prescriptions of 60 consecutive patients aged over 80 years admitted between November and December 2010 to the geriatric unit (35 beds) were evaluated following a grid. This grid contained 18 items divided into 4 themes:

- organisation of the prescriptions, drug schedule and dosage

- patients' weight

- number and type of drugs (psychotropic drugs for instance), presence of contra-indications

- biological adaptations

Results Median age was about 88 years (range: $80-96$ ) and $70 \%$ of patients were women. The median number of drugs on the 60 prescriptions was 8 (range $=1-12$ ). All prescriptions presented data on dosage and the drug schedule. Drugs were classified by therapeutic category on only one prescription. Half of the prescriptions specified the patients' weight. More than $80 \%$ of prescriptions had more than 5 drugs without redundancy concerning psychotropic drugs and non-steroidal anti-inflammatory agents. Four contra-indications were noticed among all prescriptions evaluated. All biological adaptations were followed. 
Conclusions In conclusion, we notice a good level of quality concerning prescriptions in this geriatric unit where software-assisted prescribing with pharmaceutical analysis has been effective since 2009. This software does not allow physicians to organise prescriptions by disease area. Concerning the patients' weight, senior clinicians will inform junior clinicians of its importance in the patients' file and prescription. Another evaluation will be scheduled to analyse the link between the number of drugs and the number of diseases. The final aim is to reduce the number of drugs in order to avoid drug-related adverse events.

No conflict of interest.

\section{GRP-068 EVALUATION OF SPECTRAL SPECIFICITY OF TAXANES FOR THE ON-LINE ANALYTICAL CONTROL OF HOSPITAL CHEMOTHERAPY PRODUCTION}

doi:10.1136/ejhpharm-2013-000276.068

G Sayet, L Havard, P Prognon, E Caudron. Hopital Européen Georges Pompidou, Pharmacy, Paris, France

Background On-line control of chemotherapy production is used for 27 molecules at European Georges Pompidou Hospital which corresponds to $70 \%$ of the production. Flow injection analysis (FIA) constitutes the optimal method under ultra-violet spectral data identification. If the spectra are similar, the retention time after chromatographic separation has to be used for identification. The FIA spectral differences of taxanes (docetaxel, paclitaxel, cabazitaxel) are too poor for identification.

Purpose The aim of this study was to develop an ultra-fast high performance liquid chromatographic technique for on-line analytical checking of taxane preparations.

Materials and Methods Docetaxel (Sanofi-Aventis), paclitaxel (Hospira) and cabazitaxel (Sanofi-Aventis) were prepared in sodium chloride $0.9 \%$ solution. Chromatography was performed using Prostar Varian chromatographic equipment with a Photodiode Array Detector. All the separation was done with a Polaris C18 precolumn $(3 \mu \mathrm{m}, 10 \mathrm{~mm} \times 2 \mathrm{~mm})$. The mobile phase was ultra-pure water/acetonitrile $(60-40 \mathrm{v} / \mathrm{v})$. Taxanes were eluted at the flow rate of $1.2 \mathrm{~mL} \cdot \mathrm{min}^{-1}$

Results Paclitaxel spectra obtained after chromatographic separation differ significantly from those of cabazitaxel and docetaxel, which are very similar. So the latter have to be identified by their retention time: $0.7 \mathrm{~min}$ for cabazitaxel and $0.4 \mathrm{~min}$ for docetaxel with a resolution of 1.7. Paclitaxel retention time was 0.39 with a resolution of 0.11 with docetaxel. The linear range corresponds to the therapeutic concentrations. The 3 methods were linear $(\mathrm{R}>0.995)$ with intra-day precision from $0.27 \%$ to $2.68 \%$ and inter-day precision from $0.95 \%$ to $3.7 \%$.

Conclusions Ultra-fast chromatographic separation methods have been successfully developed for the identification and quantification of 3 different taxane molecules. Less than $1 \mathrm{~min}$ is needed when spectral and retention data are combined as the main parameters.

No conflict of interest.

\section{GRP-069 EVALUATION OF THE CLINICAL IMPACT OF MEDICINES RECONCILIATION IN THE COMPIËGNE HOSPITAL CENTRE AFTER ONE YEAR OF EXPERIENCE}

doi:10.1136/ejhpharm-2013-000276.069

AC Desbuquois, F Lopes, C Aguerre, AM Liebbe. Hospital Center of Compiègne, Oise, Compiègne, France

Background The literature shows that there are errors in the drug treatment in $30 \%$ of patients at hospital admission. These medicines errors (MEs) may be continued throughout hospitalisation and can cause the patient adverse effects.

To reduce MEs and thus improve patient safety, the Compiègne Hospital Centre (HCC) has established a practise of medicines reconciliation (MR) since July 2011. Any unintentional discrepancies (UIDs) detected between the home treatment and the hospital treatment during MR are discussed and corrected with physicians to ensure continuity of the patient's medicines.

Purpose After one year of experience, the objective was to evaluate the clinical impact of our interventions on patient safety.

Materials and Methods Patients older than 65 years, hospitalised in Geriatrics and Cardiology after admission by the emergency department, were eligible for MR.

To evaluate the clinical impact of $M R$, we assessed the potential aftermath of uncorrected UIDs on patient safety. To do this, any UIDs detected and corrected were classified into two groups:

- those with a high potential clinical impact: potentially lifethreatening, that increase the length of hospitalisation and/ or decompensation/aggravation of an existing disease

- those with a low potential clinical impact.

Results 485 patients have benefited from MR, 30\% of whom had a $M E$ in their hospital prescription. Average age of patients: 84.6 years \pm 7.8 . Sex ratio M/F: 0.67 .

259 UIDs were detected of which 101 (39\%) were classified as having a high potential clinical impact. This demonstrates the importance of MR for the safety of patients at their admission.

Conclusions After one year of MR in HCC, the results were positive.

The results on the clinical impact of our intervention were very encouraging and demonstrated the importance of continuing and developing medicines reconciliation. Our experience confirms the benefit of a pharmaceutical presence in the care units to improve patient safety.

No conflict of interest.

\section{GRP-070 EVALUATION OF THE EFFECT ON PATIENT SAFETY OF A NEW LABEL DESIGN FOR MEDICINAL PRODUCTS}

doi:10.1136/ejhpharm-2013-000276.070

${ }^{1} \mathrm{H}$ Fischer, ${ }^{1} \mathrm{MH}$ Clemmensen, ${ }^{1} \mathrm{~T}$ Kart, ${ }^{2} \mathrm{P}$ Dieckmann, ${ }^{2} \mathrm{P}$ Kunstek, ${ }^{3} \mathrm{~S}$ Schytte-Hansen, ${ }^{3}$ A Hellebek. 'Amgros, The Danish Research Unit for Hospital Pharmacy, Copenhagen OE, Denmark; 'Danish Institute for Medical Simulation (DIMS), Herlev Hospital University of Copenhagen, Herlev, Denmark; ${ }^{3}$ Regional Office for Patient Safety, Capital Region of Denmark, Hvidovre, Denmark

Background In Denmark some of the medicinal products for hospitals are produced by the hospital pharmacies and registered by Amgros (SAD products). In 2007 the Danish Society for Patient Safety, Amgros, and the private foundation TrygFonden organised a design competition with the purpose of improving patient safety in label design. The winner "Medilabel Safety System" was designed by e-Types and incorporated 9 design features. The new labels were implemented in 2008

Purpose To evaluate the effects of the new label design on patient safety.

Materials and Methods Reports of medication errors related to $\mathrm{SAD}$ products before and after the introduction of the new design (2007 and 2010) were compared. Medication errors were obtained from the Danish Patient Safety Database (DPSD).

In another study patient simulation and a sorting exercise were used to evaluate the effects of the new design. 11 physicians and 9 nurses participated.

Results In 2007 and 2010 a total of 6781 and 10188 medication errors were reported to DPSD. Of these, 85 (2007) and 80 (2010) dispensing errors could be related to misinterpretation of the SAD label. Thus, while no overall effect on the number of errors related 